\title{
Sternal cleft
}

INSERM

\section{Source}

INSERM. (1999). Orphanet: an online rare disease and orphan drug data base. Sternal cleft. ORPHA:2017

Sternal cleft (SC) is a rare idiopathic cong enital thoracic malformation characterized by a sternal fusion defect, that can be complete or partial (either superior or inferior), that is usually asymptomatic in the neonatal period (apart from a paradoxical midline thoracic bulging) but that can lead to dyspnea, cough, frequent respiratory infections and increased risk of trauma-related injury to the heart, lungs and major vessels if left untreated. 